\title{
IDENTIFIKASI SOP TINGKAT PENANGANAN PENYAKIT PADA ANAK BALITA MENGGUNAKAN METODE FORWARD CHAINING (STUDI KASUS DI RUMAH SAKIT UMUM TANJUNG BALAI)
}

\author{
Khairunnisa Samosir \\ Teknik Sipil, Universitas Graha Nusantara Padangsidimpuan-Sumatera Utara \\ ftinformatika187@gmail.com
}

\begin{abstract}
ABSTRAK
Kesehatan anak menjadi faktor penting dalam perkembangan anak. Dengan Adanya SOP menjadi salah satu penilaian mutu pelayanan kesehatan baik rumah sakit pemerintah maupun swasta. Tujuan penelitian ini adalah untuk seberapa manfaat SOP yang disusun dokter untuk memberikan pelayanan yang diterima pasien. Metode yang digunakan adalah Metode Forward Chaining merupakan salah satu dapat dapat mendeteksi penyakit dengan cara mengetahui gejala terlebih dahulu . Hasil yang diperoleh dari pengujian sistem dengan menggunakan aplikasi PHP MySQ1 menunjukkan bahwa hasil diagnosa dan penyakit anak pada rumah sakit umum tanjung balai, memiliki sebanyak 10 data pasien yang telah diteliti oleh pakar dan telah melakukan pengujian kesistem mencapai akurasi $80 \%$.
\end{abstract}

Kata kunci : Forward Chaining, Rules, PHP MySQL, Sistem Pakar, Diagnosa Penyakit.

\begin{abstract}
Children's health is an important factor in children's development. With the existence of SOPs, it becomes one of the assessments of the quality of health services both government and private hospitals. The purpose of this study is to find out the benefits of SOPs compiled by doctors to provide services received by patients. The method used is the Forward Chaining Method is one that can detect disease by knowing the symptoms first. The results obtained from testing the system using the PHP MySQ1 application show that the results of diagnoses and pediatric illnesses at Tanjung Balai Public Hospital, have as many as 10 patient data that have been studied by experts and have carried out system testing reaching $80 \%$ accuracy.
\end{abstract}

Keywords: Forward Chaining, Rules, Diagnoses, PHP MySQl, Expert System, diagnoses of the disease

\section{PENDAHULUAN}

Perkembangan ilmu kedokteran juga mengalami kemajuan yang pesat dengan ditemukannya penyakit-penyakit yang tidak ditemukan sebelumnya. Para ahli terus menemukan solusi untuk mengatasi permasalahan yang sebelumnya belum ditemukan solusi terbaru sehingga memudahkan bagi pasien untuk dapat berkonsultasi dan menangani kepada dokter pakar. Kesehatan adalah yang paling berharga bagi manusia terutama bagi kedua orang tua terhadap anak tercintanya, karena siapa saja bisa mengalami gangguan kesehatan. Termasuk pada anak balita sangat rentan terhadap penyakit sehingga terjadi ketakutan tersendiri bagi orang tua. Salah satu upaya untuk menjaga 
keselamatan pasien, dengan menerapkan Standart Operational Prosedure (SOP) dalam setiap tindakan perawat. Keselamatan pasien bertujuan untuk meningkatkan pelayanan dan menghindari tuntutan malpraktek. Standart Operational Procedure (SOP) adalah standart yang harus dijadikan acuan dalam memberikan setiap pelayanan. Penyakit yang sering diderita pada anak adalah penyakit pada sidrom. Sindrom iritasi usus adalah yang ditandai dengan sakit perut dan perubahan pola buang air besar. Rasa nyeri dapat terjadi pada siapa anak ataupun orang dewasa penyebab dapat difaktorkan pada pola makanan, pada setres dan depresi bisa dapat memperburuk gejala (Enrique, Fermin, Javier dan Constanza. 2017). Permasalahan ketepatan diagnosis karena di rumah sakit umum tanjung balai sumatera utara ini karena pernah sebelumnya terjadi keterlambatan dalam mendiagnosis gejala dan pasien, Keterlambatan diagnosis karena banyaknya jumlah pasien yang datang dan harus terlebih dahulu mendaftar sehingga memakan waktu yang sangat lama dalam penanganan penyakit anak. Sistem pakar berdasarkan aturan adalah sistem cerdas yang membuat keputusan cepat dan berulang berdasarkan pada pengetahuan. Basis pengetahuan dapat terbentuk melalui mengawasi ketiga kategori ini: faktual, sekuensial dan logis. Sistem berdasarkan aturan dapat diimplementasikan baik forward atau backward chaining (Sajid dan Hussain.
2018).

\section{Pengertian Sistem Pakar}

Sistem Pakar adalah Suatu sistem yang dirancang untuk dapat menirukan keahlian seorang pakar dalam menjawab semua pertanyaan dan memecahkan suatu masalah. Sistem pakar akan memberikan pemecahan suatu masalah yang didapat dari dialog dengan pengguna, dengan bantuan sistem pakar seseorang yang bukan pakar atau ahli dapat menjawab pertanyaan, menyelesaikan masalah serta mengambil keputusan yang biasanya dilakukan oleh seorang pakar (Yuhandri, 2018).

\section{Struktur Sistem Pakar}

Struktur sistem pakar memiliki dua jenis adalah lingkungan pengembangan (development environment), dan lingkungan konsultasi (consultant environment). Dimana pada lingkungan pengambilan dilakukan ada saat membuat sistem pakar hanya untuk komponenkomponen saja, namun pada lingkungan konsultasi dapat digunakan hanya pengguna yang untuk berkonsultasi pada pakar langsung sehingga mendapatkan hasil yang telah diuji. Seperti halnya pada seorang pasien mendapatkan suatu penyakit dan membutuhkan seorang dokter pakar untuk dapat berkonsultasi dan dapat membantu 
dan menangani segala permasalahan.

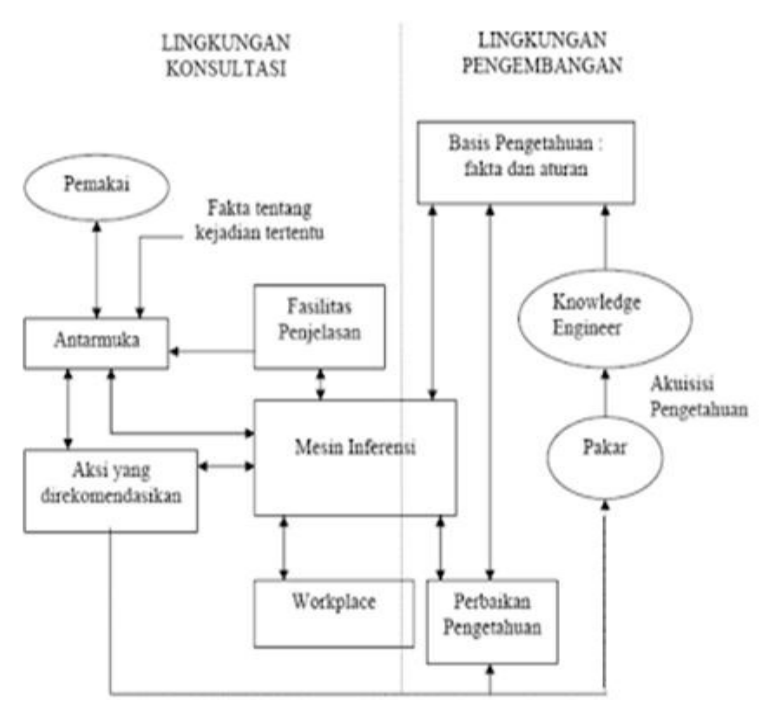

Gambar 1. Struktur Sistem Pakar

(Kusumadewi, 2003)

\section{Forward Chaining}

Menurut pendapat (Wiwi Verina, 2015), Forward chaining adalah tahap pencarian yang berawal dari fakta yang didapat, kemudian fakta yang didapat akan disamakan kembali dengan menggunakan Rules IF-THEN. Jika hasilnya yang didapat sama (IF), maka Rule tersebut dapat dieksekusi. Bila Rule dieksekusi, maka fakta baru (THEN) akan ditambah ke dalam Database. Jika setiap Rule memiliki sama, maka akan dimulai dari Rule teratas. Setiap Rule hanya boleh dieksekusi satu kali. Dengan menggunakan metode yang dilakukan oleh seorang pakar. Faktanya seorang pakar dapat menangani dalam mendiagnosa penyakit pada pasien, dengan menggunakan forward chaining hasilnya akan lebih cepat untuk menemukan suatu persoalan.

\section{PHP}

Hypertext Processor (PHP) adalah bahasa pemrogrman yang digunakan untuk membuat suatu web yang pada dasarnya membutuhkan PHP. PHP bukanlah sebuah bahasa pemrograman yang hanya digunakan untuk men-desain website. PHP menggunakan script sebagai pelengkap untuk membuat suatu pekerjaan yaitu sebuah website. Namun jika untuk membuat halaman web, sebenarnya PHP bukanlah pemrograman yang wajib digunakan. Kita bisa menggunakan beberapa alat bantu seperti HTML (Ana dan Tatang, 2017).

\section{Database My SQL}

"SQL merupakan singkatan dariStructured Query Language. SQL merupakan bahasa permintaaan pada suatu database atau SMBD tertentu. Dengan kata lain, SQL adalah perintah atau bahasa yang melekat di dalam SMBD, seperti MySQL Server, MsSQL, PostgreSQL, Interbase, dan Oracle" (Eri Mardiani dan Nur Rahmansyah,2016). MySQL dikembangkan oleh sebuah perusahaan pengembang software dan konsultan database di Swedia bernama MySQL AB, yang kala itu bernama TcXDataKonsult AB sejak 1994-1995 (Ana dan Tatang, 2017).

\section{Standart Operational Procedure (SOP)}

SOP adalah Menurut Sailendra, Standar Operasional Prosedur (SOP) adalah panduan yang digunakan untuk memastikan kegiatan operasional organisasi atau perusahaan berjalan dengan lancar (Moekijat, 2008). 


\section{METODE PENELITIAN}

Pada penelitian kali ini akan diproses cara kerja permasalahan. Fungsi dari penelitian saat ini dapat mempermudah oleh pakar dalam mendiagnosa penyakit yang diderita seseorang dan memberikn arahan pada suatu masalah. Penelitian pada sistem pakar yakni melihat masalah pendiagnosaan penyakit pada anak dengan metode Forward Chaining yang sangat membantu.

Tujuan penelitian yakni melihat masalah pendiagnosaan penyakit pada anak dengan menggunakan metode Forward chaining dan bahasa pemograman PHP. Dalam prosesnya diperlukan literatur yang berguna untuk pemahaman konsep dan pendalaman teori tentang metode yang dibahas yaitu Forward chaining dari beberapa jurnal. Pada tahap berikutnya yakni pengumpulan data dilakukan observasi secara langsung.

\section{Kerangka Kerja}

Pengujian Dengan Forward Chaining

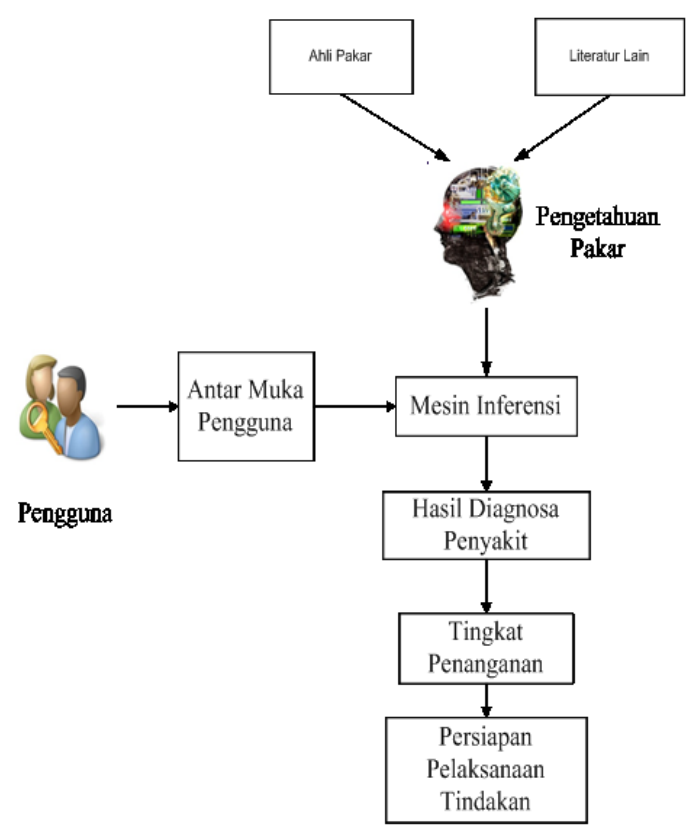

Gambar 2. Kerangka Kerja Penelitian
Uraian dari kerangka kerja penelitian pada gambar 3.1 adalah sebagai berikut:

1. Ahli Pakar

Orang yang ahli dalam bidang keahlian tertentu, yang dapat memutuskan suatu permasalahan.

2. Sumber Pengetahuan lainnya

Suatu bahan reverensi atau sumber peneliti sebelumnya yang menghasilkan suatu karya tulis atau penelitian lainnya yang ditemui berbadasarkan menurut pendapat sebelumnya sebagai sumber pengetahuan.

3. Pengetahuan Pakar

Dalam pengetahuan pakar menjelaskan bahwa memahami tentang pakar, seorang yang memiiki pengetahuan dalam bidang pakar, sepereti pakar dalam bidan diagnosa penyakit.

4. Pengguna

Pengguna/Pasien yang ingin mendeteksi faktor gejala yang saat ini terjadi serta konsultasi kepada seorang dokter pakar untuk mendapatkan penjelasan dan menangani gejala penyakit.

5. Antar Muka Pengguna

Merupakan orang yang berkonsultasi secara langsung yang berhubungan langsung dengan pengguna (user).

6. Mesin Inferensi

Merupakan otak dari pakar tersebut, yang berfungsi untuk memmandu proses permasalahan terhadap suatu kondisi dari pengetahuan yang tersedia. Fungsi lainnya adalah memberikan pertanyaan kepada user untuk mendapatkan hasil dari diagnosa gejala tersebut.

7. Hasil Diagnosa Penyakit 
Hasil dari evaluasi adalah untuk membantu mengatasi tingkat penanganan penyakit pada anak. Hasil ini dapat membantu dan mempermudah pekerjaan seorang dokter pakar, dan tahapan tahapan selanjutnya dilaksanakan untuk mengatasi tingkat permasalahan.

8. Tingkat Penanganan

Tingkat penanganan penyakit pada anak dilakukan melalui upaya pencegahan, pengendalian, dan pemberantasan. Upaya penanganan dilakukan bermacam-macam untuk mengtasi masalah, yaitu tingkat penanganan tindak lanjut dan tingkat penanganan sedang. Dengan adanya tingkat penanganan, akan membantu orangtua dalam menangani.

9. Persiapan pelaksanaan Tindakan

Setelah tingkat penanganan dilanjutkan, selanjutnya persiapan pelaksanaan tindakan dilakukan oleh pakar. Dimana sistem sudah mengeluarkan hasil diagnosa pasien dan persiapan pelaksaan tindakan selanjutnya yang akan dilakukan.

\section{Tahapan Analisa dan Perancangan}

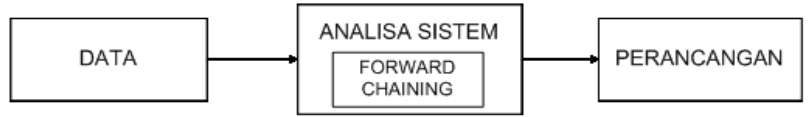

Gambar 3. Bagan Alir Analisa dan

Perancangan

\section{Data}

Data yang digunakan pada penelitian ini adalah data yang diambil tentang penyakit pada anak yang dikeluarkan oleh Rumah Sakit Umum Tanjung Balai. Data ini dipakai sebagai uji coba untuk mendiagnosa penyakit pada anak. Data tersebut lalu diolah dengan menggunakan metode Forward Chaining yang berbasis Website berdasarkan bantuan seorang Pakar.

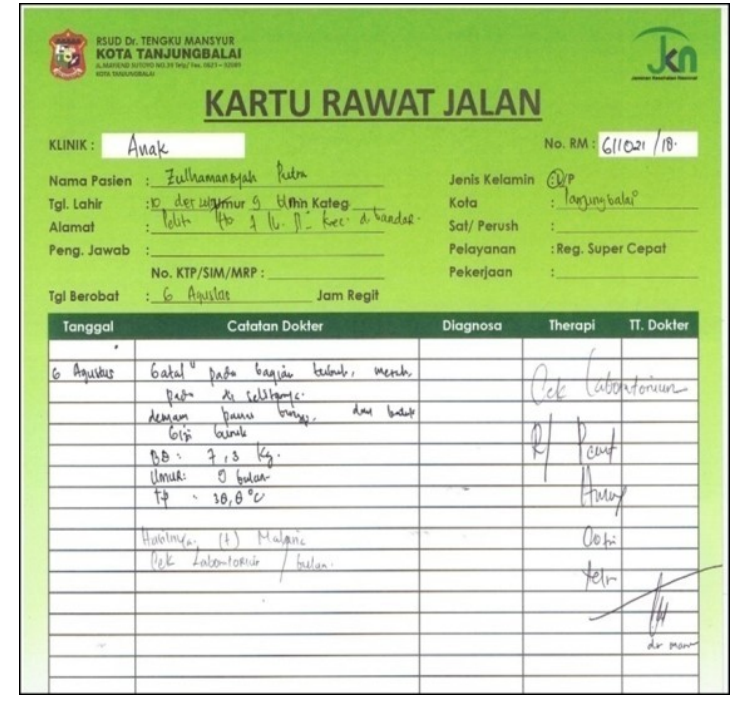

Gambar 4. Kartu Rawat Jalan Analisa Sistem

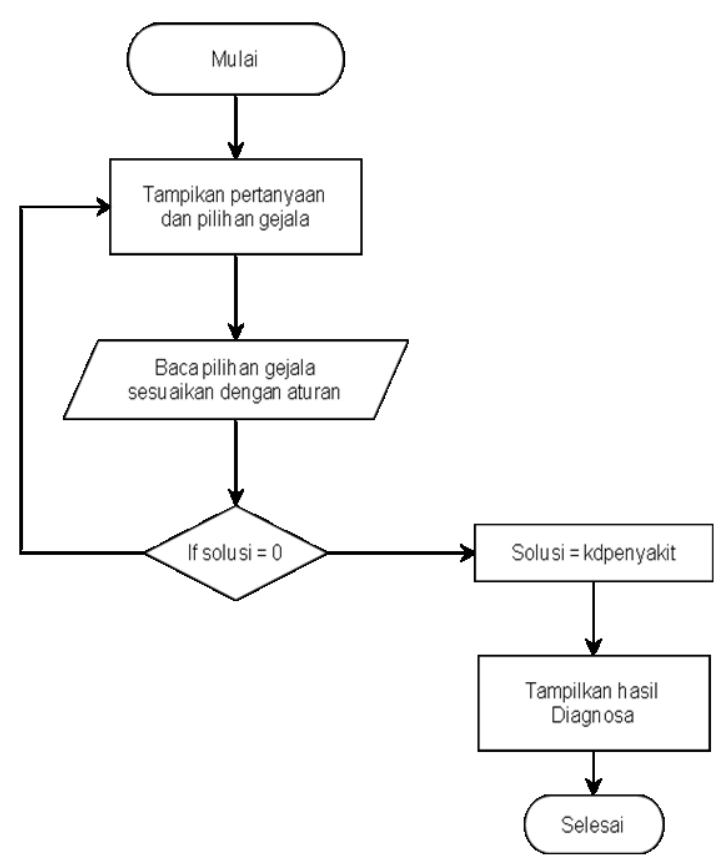

Gambar 5. Flowchart Proses Sistem Pakar dengan Forward Chaining

\section{Daftar Aturan (Rule) Untuk Mendeteksi Penyakit Anak (Lanjutan)}

Tabel 1. Aturan Rule

\begin{tabular}{cl}
\hline No & \multicolumn{1}{c}{ Aturan (Rule) } \\
\hline 1 & IF Demam is true \\
& AND Panas is true \\
& AND Gigi terkatup is true
\end{tabular}


AND Bola mata tampak melihat keatas is true

AND Muntah is true

AND Tangan dan kaki kejang is true

THEN Kejang demam

2 IF kesulitan bernafas is true

AND Demam makin parah is true

AND Anak tampak lemas, rewel, dan tidak nyaman is true

AND Wajah pucat is true

AND Nafas berbunyi setelah batuk is

true

THEN Batuk

3 IF Sangat lemah is true

AND Buang air besar lebih dari $4 x$ sehari is true

AND Gelisah is true

AND Kulit kering is true

AND Muntah terus menerus is true

AND Nadi melemah sampai tak teraba is true

THEN Diare

4 IF Sakit tenggorokan is true

AND Sulit bernafas is true

AND Darah lendir kotoran is true

AND Demam is true

AND Kelenjar getah bening dileher membesar dan terasa sakit is true

AND Radang lidah disertai rasa sakit is

true

THEN Difteri

5 IF Pucat, kurus, perut kembung, dan kehilangan massa otot pada keempat anggota geraknyais true

AND kurangnya nafsu makan is true

AND Pusing is true

AND Sistem kekebalan tubuh yang

rendah is true

AND Pertumbuhan yang lambat is true

THEN Gizi buruk

\section{Menentukan Pohon Keputusan}

Berdasarkan aturan diatas terlihat baha setiap faktor yang mempengaruhi hasil mendeteksi penyakit anak yang memiliki gejala yang mempengaruhi penyakit tersebut.pada tabel relasi gejala dan penyakit pada anak tersebut, maka dapat dibuat pohon keputusan sebagai berikut :

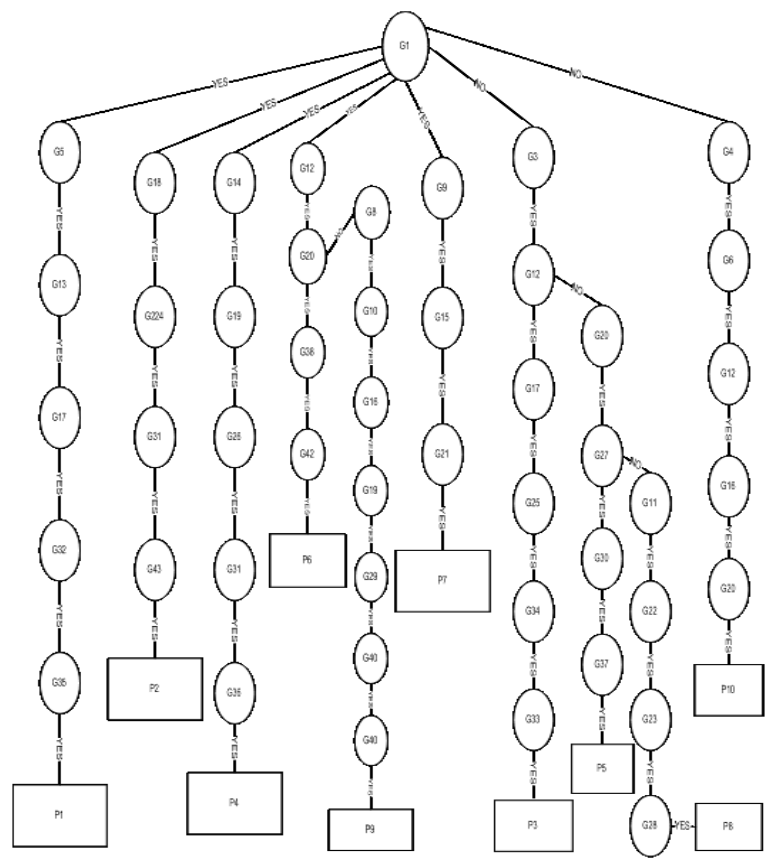

Gambar 6. Pohon Keputusan

\section{HASIL DAN PEMBAHASAN}

\section{Tampilan Halaman Pasien}

Form halaman pasien digunakan untuk melakukan proses input data gejala penyakit anak. Telebih dahulu untuk masuk ke dalam sistem Website harus memiliki account jika belum memiliki account diwajibkan untuk mendaftar. Berikut tampilan yang terdiri dari beberapa menu yaitu, Home, Profil, Konsultasi dan Login. Dapat dilihat pada gambar 7.

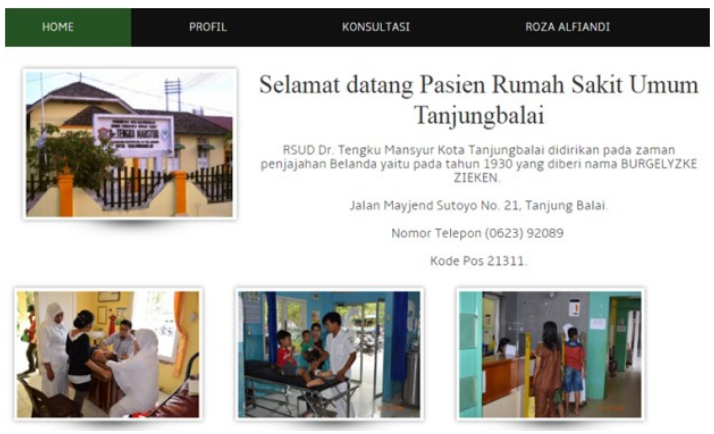

Gambar 7. Tampilan Halaman Pasien 


\section{Hasil Pengujian Pakar}

Pengujian terhadap pasien yang di uji adalah data yang didapat dari penelitian sebanyak 10 (Pasien), dapat dilihat pada tabel 2.

Tabel 2. Rekapitulasi Pengujian Sistem Terhadap Para Pasien

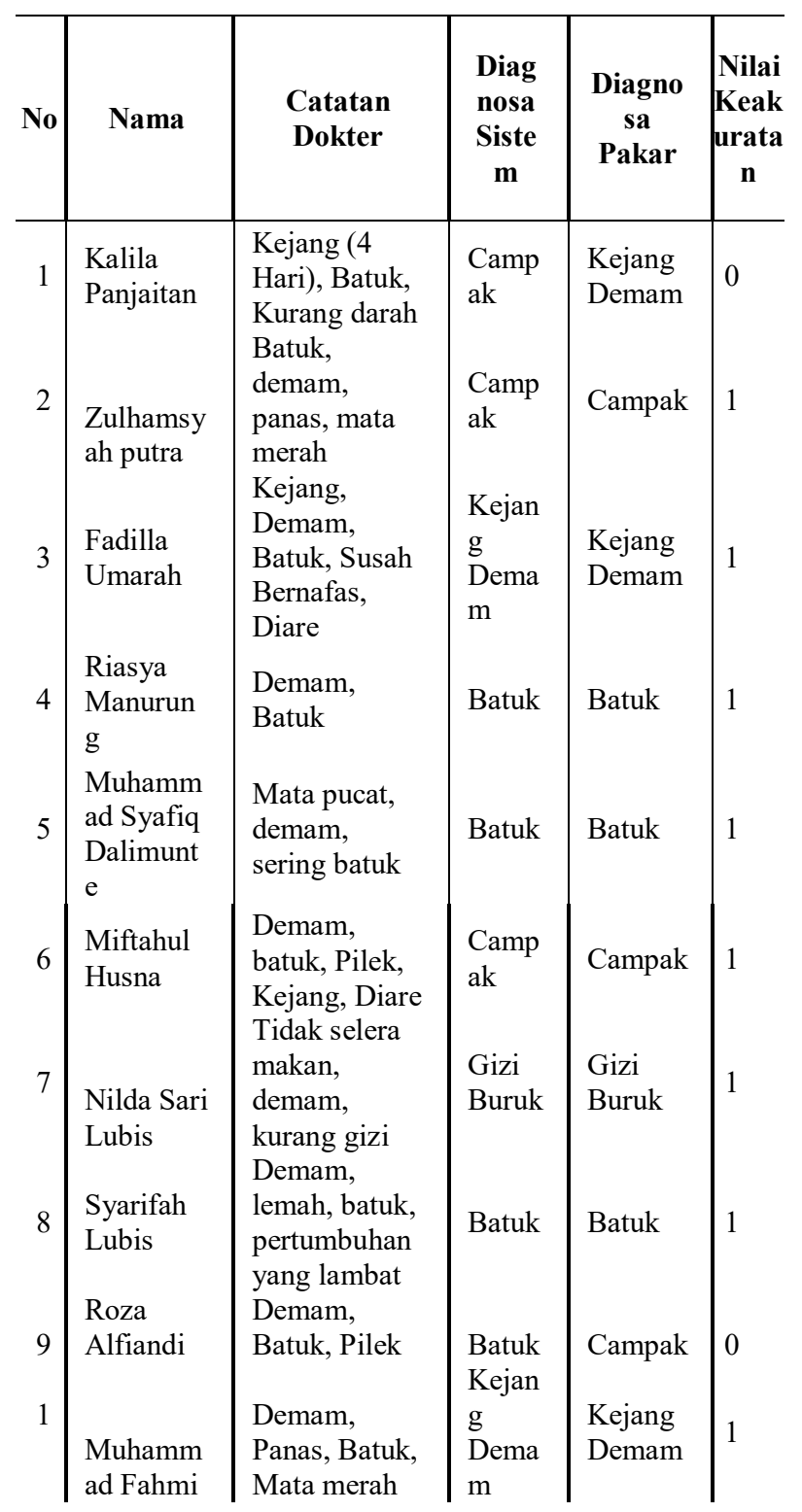

Berikut rumus yang digunakan untuk menghitung probabilitas akurat pada penyakit anak, berikut dapat dilihat dibawah ini :

Pjumlah (Akurat) $=($ jumlah

akurat $) /($ jumlah data $) \times 100 \%$

Pjumlah $($ Tidak Akurat $=($ jumlah akurat) $/($ jumlah data $) \times 100 \%$
Jika dihitung probabilitasnya, akan diperoleh hasil sebagai berikut :

$$
\begin{aligned}
& \text { P } 10(\text { akurat })=8 / 10 \times 100 \%=80 \% \\
& \text { P } 10(\text { tidak }
\end{aligned}
$$$$
\text { akurat })=2 / 10 \times 100 \%=20 \%
$$

Dari hasil probabilitas yang dicapai $80 \%$, dengan metode Forward Chaining yang digunakan pada sistem ini menggunakan representasi pengetahuan berupa aturan pada gejala, menunjukkan bahwa sistem yang telah digunakan cukup baik untuk dapat digunakan dalam aplikasi berbasis Website. Namun demikian, metode Forward Chaining kurang tepat untuk kasus diagnosa penyakit yang didapat. Karena penalaran dokter mengarah pada kesimpulan tentang jenis penyakit, sehingga sistem sedikit bingung untuk mengarahkan gejala yang dialami pasien.

\section{KESIMPULAN}

Berdasarkan penelitian dan pembahasan yang dilakukan, maka dapat disimpulkan beberapa hal sebagai berikut :

1. Pada penelitian ini sudah dikembangkan aplikasi berbasis Website dengan metode forward chaining untuk mendiagnosis penyakit pada anak dengan mencapai akurasi $80 \%$ dari 10 data pasien di rumah sakit umum tanjung balai.

2. Adanya mutu pelayanan dalam SOP telah membantu dalam menangani pasien dengan cepat.

3. Dengan adanya aplikasi ini dapat membantu masyarakat umum dalam mendiagnosa penyakit pada anak dengan cepat tanpa harus bertemu langsung dengan dokter. 


\section{DAFTAR PUSTAKA}

[1]. Chukwudebe, G. A., Ekwuwune, E., \& Nkuma-Udah, K. I. (2017). Medical diagnosis expert system for Malaria and related diseases for developing Countries. 2017 IEEE 3rd International Conference on ElectroTechnology for National Development (NIGERCON)", 24-29. https://doi.org/10.1109/NIGERCON.2017.82 $\underline{81875}$

[2]. Djaja, S., Wiryawan, Y., \& Maisya, I. B. (2009). Tren Penyakit Penyebab Kematian Bayi Dan Anak Balita Di Indonesia Dalam Periode Tahun 1992-2007. Jurnal Ekologi Kesehatan, 8(4 Des), 1100-1107. Retrieved from

http://ejournal.litbang.depkes.go.id/index.ph $\mathrm{p} / \mathrm{jek} /$ article/view/1687

[3]. Maharani, S., Dengen, N., Saputra, G. Y., Khairina, D. M., \& Hatta, H. R. (2016). Expert system applications for early diagnosis teeth and oral disease in children. ICITACEE 2015 - 2nd International Conference on Information Technology, Computer, and Electrical Engineering: Green Technology Strengthening in Information Technology, Electrical and Computer Engineering Implementation, Proceedings, 87-91.

https://doi.org/10.1109/ICITACEE.2015.74 37776

[4]. Novaliendry, D., Yang, C. H., \& Denno Guara Labukti, A. Y. (2015). The expert system application for diagnosing human vitamin deficiency through forward chaining method. International Conference on ICT Convergence 2015: Innovations Toward the IoT, $5 \mathrm{G}$, and Smart Media Era, ICTC 2015, 53-58. https://doi.org/10.1109/ICTC.2015.7354493

[5]. Ramadhan, M. (2011). Sistem Pakar Dalam Mengidentifikasi Penyakit Kanker Pada Anak Sejak Dini dan Cara Penanggulangannya. Jurnal SAINTIKOM, 10(2), 125-135.

[6]. Rey, E., Mearin, F., Alcedo, J., Ciriza, C., Delgado-Aros, S., Freitas, T., Serra, J. (2017). Optimizing the Use of Linaclotide in Patients with Constipation-Predominant Irritable Bowel Syndrome: An Expert Consensus Report. Advances in Therapy, 34(3), 587-598. https://doi.org/10.1007/s12325-016-0473-8

[7]. Sajid, A., \& Hussain, K. (2018). Rule Based (Forward Chaining/Data Driven) Expert System for Node Level Congestion Handling in
Opportunistic Network. Mobile Networks and Applications, 23(3), 446455. https://doi.org/10.1007/s11036018-1016-0

[8]. Shesternikova, O. P., Agafonov, M. A., Vinokurova, L. V., Pankratova, E. S., \& Finn, V. K. (2016). Intelligent system for diabetes prediction in patients with chronic pancreatitis. Scientific and Technical Information Processing, 43(5-6), 315-345. https://doi.org/10.3103/S01476882160 $\underline{50051}$

[9]. Supartini, W., \& Hindarto. (2016). Sistem Pakar Berbasis Web Dengan Metode Forward Chaining Dalam Mendiagnosis Dini Penyakit Tuberkulosis di Jawa Timur. Kinetik, 1(3), 147-154. https://doi.org/10.22219/kinetik.v1i3.1 23

[10]. Ula, M., Mursyidah, Hendriana, Y., \& Hardi, R. (2017). An expert system for early diagnose of vitamins and minerals deficiency on the body. 2016 International Conference on Information Technology Systems and Innovation, ICITSI 2016 - Proceedings, $0-5$.

https://doi.org/10.1109/ICITSI.2016.78 $\underline{58225}$

[11]. Veazey, S. E., Valentino, A. L., Low, A. I., McElroy, A. R., \& LeBlanc, L. A. (2016). Teaching Feminine Hygiene Skills to Young females with Autism Spectrum Disorder and Intellectual Disability. Behavior Analysis in Practice, 9(2), 184-189. https://doi.org/10.1007/s40617-015$\underline{0065-0}$ 